\title{
Correction to: Proteomic identification and characterization of hepatic glyoxalase 1 dysregulation in non-alcoholic fatty liver disease
}

Christos Spanos ${ }^{1}$, Elaina M. Maldonado ${ }^{1}$, Ciarán P. Fisher ${ }^{1}$, Petchpailin Leenutaphong ${ }^{1}$, Ernesto Oviedo-Orta ${ }^{1}$, David Windridge ${ }^{1}$, Francisco J. Salguero ${ }^{1}$, Alexandra Bermúdez-Fajardo ${ }^{1}$, Mark E. Weeks' ${ }^{2}$, Caroline Evans ${ }^{3}$, Bernard M. Corfe ${ }^{4}$, Naila Rabbani ${ }^{5}$, Paul J. Thornalley ${ }^{5}$, Michael H. Miller $^{6}$, Huan Wang ${ }^{6}$, John F. Dillon', Alberto Quaglia', Anil Dhawan ${ }^{7}$, Emer Fitzpatrick ${ }^{7}$ and J. Bernadette Moore ${ }^{1,8^{*}}$

\section{Correction}

Following publication of the original article [1], J. Bernadette Moore noticed that her name was incorrectly listed on PubMed as:

Given name: J.

Surname: Bernadette Moore

This should in fact be:

Given name: J. Bernadette

Surname: Moore

\section{Author details}

'Department of Nutritional Sciences, Faculty of Health and Medical Sciences, University of Surrey, Guildford, Surrey GU2 7XH, UK. ${ }^{2}$ Institute of Child Health, University College London, WC1N 1EH, London, UK. ${ }^{3}$ Biological and Systems Engineering Group, ChELSI Institute, Department of Chemical and Biological Engineering, University of Sheffield, S1 3JD, Sheffield, UK. ${ }^{4}$ Molecular

Gastroenterology Research Group, Department of Oncology and Insigneo Institute for in silico Medicine, University of Sheffield, S10 2RX, Sheffield, UK. ${ }^{5}$ Clinical Sciences Research Laboratories, Warwick Medical School, University of Warwick, University Hospital, Coventry CV2 2DX, UK. ${ }^{6}$ Medical Research Institute, University of Dundee, Ninewells Hospital and Medical School, Dundee DD1 9SY, UK. PPaediatric Liver, GI and Nutrition Centre, King's College London School of Medicine, London SE5 9RS, UK. ${ }^{8}$ School of Food

Science and Nutrition, University of Leeds, Leeds LS2 9JT, UK.

Received: 4 June 2018 Accepted: 4 June 2018

Published online: 25 June 2018

\section{Reference}

1. Spanos C, Maldonado EM, Fisher CP, Leenutaphong P, Oviedo-Orta E,

Windridge D, Salguero FJ, Bermúdez-Fajardo A, Weeks ME, Evans C, Corfe BM, Rabbani N, Thornalley PJ, Miller MH, Wang H, Dillon JF, Quaglia A, Dhawan A,

Fitzpatrick E, Bernadette Moore J. Proteomic identification and characterization

* Correspondence: j.b.moore@leeds.ac.uk

'Department of Nutritional Sciences, Faculty of Health and Medical Sciences, University of Surrey, Guildford, Surrey GU2 7XH, UK

${ }^{8}$ School of Food Science and Nutrition, University of Leeds, Leeds LS2 9JT, UK

Full list of author information is available at the end of the article of hepatic glyoxalase 1 dysregulation in non-alcoholic fatty liver disease. Proteome Sci. 2018;16:4. https://doi.org/10.1186/s12953-018-0131-y.

(0) The Author(s). 2018 Open Access This article is distributed under the terms of the Creative Commons Attribution 4.0 International License (http://creativecommons.org/licenses/by/4.0/), which permits unrestricted use, distribution, and reproduction in any medium, provided you give appropriate credit to the original author(s) and the source, provide a link to the Creative Commons license, and indicate if changes were made. The Creative Commons Public Domain Dedication waiver (http://creativecommons.org/publicdomain/zero/1.0/) applies to the data made available in this article, unless otherwise stated.
} 